\title{
Molecular characterization of egg envelope glycoprotein ZPD in the ovary of Japanese quail (Coturnix japonica)
}

\author{
Tsukasa Sato, Mihoko Kinoshita, Norio Kansaku, Kenichi Tahara², Akira Tsukada², Hiroko Ono ${ }^{2}$, \\ Takashi Yoshimura ${ }^{2}$, Hideo Dohra ${ }^{3}$ and Tomohiro Sasanami \\ Department of Applied Biological Chemistry, Faculty of Agriculture, Shizuoka University, 836 Ohya, Shizuoka 422- \\ 8529, Japan, 'Laboratory of Animal Genetics and Breeding, Azabu University, Fuchinobe, Sagamihara 229-8501, \\ Japan, ${ }^{2}$ Graduate School of Bioagricultural Sciences, Nagoya University, Furo-cho, Chikusa-ku, Nagoya 464-8601, \\ Japan and ${ }^{3}$ Institute for Genetic Research and Biotechnology, Shizuoka University, 836 Ohya, Shizuoka 422-8529, \\ Japan
}

Correspondence should be addressed to T Sasanami; Email: atsasan@agr.shizuoka.ac.jp

\begin{abstract}
The egg envelope surrounding avian oocytes exhibits a three-dimensional network of coarse fibers between the granulosa cells and the oocyte. Our previous studies have demonstrated that one of the matrix's components, ZP3, is synthesized in the ovarian granulosa cells. Another component, ZP1, which is critically involved in triggering the sperm acrosome reaction, is synthesized in the liver. We have previously isolated cDNAs encoding quail ZP3 and ZP1, and we now report the isolation of cDNA encoding quail ZPD. By RNase protection assay and in situ hybridization, we have demonstrated that ZPD transcripts are restricted to the granulosa cells of preovulatory follicles. The expression level of ZPD increased progressively during follicular development, and the highest expression was observed in the largest follicles. Western blot analyses using the specific antibody against ZPD indicate that the 40 kDa protein is the authentic ZPD, and the contents of ZPD protein also increased during follicular development. Moreover, we found that the addition of FSH to the culture media enhances the ZPD secretion in the cultured granulosa cells. Two-dimensional gel electrophoresis revealed the presence of several ZPD isoforms with different pI values ranging from 5.5 to 7 . Immunohistochemical analyses indicate that the materials recognized with anti-quail ZPD antibody were accumulated in the egg envelope of large yellow follicles. These results demonstrate the presence of ZPD protein in the egg envelope, and that the amount of ZPD in the egg envelope as well as the mRNA in the cells increases at the latter stages of folliculogenesis.
\end{abstract}

Reproduction (2009) 137 333-343

\section{Introduction}

The avian egg is surrounded by multiple layers of different extracellular matrices, including an inner layer of vitelline membrane, continuous membrane, and an outer layer of vitelline membrane (Bellairs et al. 1963). At the time of ovulation, the avian oocyte is only surrounded by the inner layer of vitelline membrane, also referred to as the perivitelline layer (PL), which is a rough meshwork of thick filaments mainly composed of glycoproteins (Wyburn et al. 1965). PL is a homolog of the egg envelope in other vertebrates, the zona pellucida (ZP) in mammals, the vitelline membrane in amphibians and the chorion in teleosts. The vertebrate's egg envelope serves several functions in the process of fertilization, including species-specific sperm-egg binding, induction of the acrosome reaction, and prevention of polyspermy (McLeskey et al. 1998). Although the penetration of the PL by supernumerary spermatozoa is found regularly in birds, the PL behaves in a manner analogous to the ZP in mammalian species (Howarth 1990).

These egg envelopes are mainly constructed of glycoproteins belonging to different subclasses of the ZP gene family (Spargo \& Hope 2003, Conner et al. 2005, Smith et al. 2005). The components of this matrix include three glycoproteins (i.e., ZP1, ZP2, and ZP3, which are also known as ZPB1, ZPA, and ZPC respectively, according to Spargo \& Hope (2003) and Smith et al. (2005)) in most mammalian species (Harris et al. 1994) and four glycoproteins in several organisms including humans, bonnet monkeys, and rats (ZP1, ZP2, ZP3, and ZP4 (ZPB2); Lefievre et al. 2004, Hoodbhoy et al. 2005, Ganguly et al. 2008), while non-mammalian vertebrates such as amphibians (i.e., Xenopus laevis and X. tropicalis), five ZP glycoproteins (ZP2, ZP3, ZP4, ZPD, and $Z P A X)$ have been identified (Lindsay et al. 2003, Goudet et al. 2008). ZP gene family proteins are characterized by a highly conserved amino acid sequence called the ZP domain, consisting of about 
260 amino acid residues with eight or ten conserved Cys residues (Bork \& Sander 1992).

In avian species, at least two glycoproteins have been identified as the component of PL, ZP1, and ZP3 in quail (Pan et al. 2001, Sasanami et al. 2003b) and in chickens (Waclawek et al. 1998, Takeuchi et al. 1999, Bausek et al. 2000). In addition, a recent study has revealed that a new member of the ZP protein family, ZPD, is a structural component in chicken PL (Okumura et al. 2004). These glycoproteins coordinately assemble into the fibrous matrix on the surface of the oocyte (Sasanami et al. 2004), and the one of its major components, ZP1, has the ability to induce the sperm acrosome reaction in Japanese quail (Sasanami et al. 2007).

We have previously cloned the cDNA encoding ZP3 (GenBank accession no. AB012606) and ZP1 (GenBank accession no. AB061520) of the quail PL. Although the hormonal control as well as the machinery of posttranslational modification of the major components has been investigated in detail (Pan et al. 2001, Sasanami et al. 2002, 2003 b, 2003c), knowledge of the remaining components is still lacking. In the present study, we have cloned a novel constituent of quail PL protein, ZPD, which was first discovered in the egg envelope of $X$. laevis (Lindsay et al. 2002), and showed that the ZPD gene is expressed in the granulosa cells of the preovulatory follicles. Moreover, we also provide details about the biochemical properties of the ZPD protein as well as the expression pattern of the gene.

\section{Results \\ Cloning of quail ZPD}

The degenerate PCR amplified a product of $684 \mathrm{bp}$ from quail granulosa cells, and RACE procedures led to the isolation of $5^{\prime}$ and $3^{\prime}$ ends of the cDNA covering the open reading frame and UTRs (Fig. $1 \mathrm{~A}$ ). The sequences have been deposited in the GenBank database (accession number: AB301422).

The isolated cDNA encoded 420 amino acids, including a predicted 21-amino acid signal peptide (Fig. 1A). As other ZP proteins, ZPD contains a ZP domain $\left(\mathrm{Ala}^{86}-\mathrm{Leu}^{342}\right.$ ) and a consensus furin-cleavage site $\left(\mathrm{Arg}^{344}-\mathrm{Ser}^{345}-\mathrm{Lys}^{346}-\mathrm{Arg}^{347}\right.$ ) near the $\mathrm{C}$ terminus. Interestingly, unlike other ZP proteins, quail ZPD possesses an additional consensus furin-cleavage site in the upstream of the ZP domain ( $\mathrm{Arg}^{39}-\mathrm{Ala}^{40}-\mathrm{Lys}^{41}$ $\mathrm{Arg}^{42}$ ), indicating the possibility that the $\mathrm{N}$ terminus as well as the C-terminal region of the newly synthesized precursor protein could be proteolytically processed by furin-like protease. From the $\mathrm{N}$-terminal amino acid sequence analysis, we found that the first seven residues are Ser-X-Asp-Ala-X-Met-Pro, which corresponded to the sequence from $\mathrm{Ser}^{43}$ to $\mathrm{Pro}^{49}$ of the deduced amino acid sequence from the cDNA. This result also supports the hypothesis that the $\mathrm{N}$-terminal proteolytic cleavage of the precursor for ZPD occurs at the consensus furincleavage site, $\mathrm{Arg}^{39}-\mathrm{Ala}^{40}-\mathrm{Lys}^{41}-\mathrm{Arg}^{42}$. There are four putative $\mathrm{N}$-glycosylation sites in the translated protein that are completely conserved with chicken homolog and the three of them are common with the frog counterpart (Fig. 1B). A putative transmembrane domain could be identified in the C-terminal region of the protein $\left(\mathrm{Ile}^{394}\right.$ $\mathrm{Ala}^{410}$ ) with a short cytoplasmic tail. We identified ten Cys residues in the ZP domain of the quail ZPD (Fig. 1B). Among these, ten Cys are conserved between quail and chicken, and eight between quail and X. laevis (Fig. 1B), suggesting that their three-dimensional structures are similar to each other. Although the overall similarity of the amino acid sequence of quail ZPD with its frog counterpart was limited, these common features suggest that our clone is an authentic member of ZPD.

\section{Pattern of ZPD $m R$ RA expression in vivo}

To determine the localization of ZPD transcripts, we analyzed the total RNA isolated from various tissues of laying quail using a gene-specific RNase protection assay (Fig. 2). As shown in the figure, a single protected probe fragment was detected only in the granulosa cells of the largest follicles (lane Granulosa antisense probes (AS)). No such signal above the background was observed when the same sample was hybridized with sense probe (lane Granulosa sense probes (S)), confirming the specificity of the hybridization. These results demonstrated that the expression of ZPD gene is restricted to the granulosa cells in the quail ovary.

The temporal accumulation of the ZPD transcripts during follicular development was observed by an RNase protection assay. As shown in Fig. 3A, the band of the protected fragment in the F3 as well as F2 was faint (lanes 1 and 2), whereas the intensity of the band dramatically increased when the RNA derived from the F1 was detected (lane 3). The protected fragment was not detected when the sample was prepared from small yellow follicles (data not shown). These results are in accord with the in situ hybridization data (Fig. 3B), where the intense signal was detected in the outer peripheral region of the follicular wall of F1. In comparison with that of the F1 specimens, the intensity of the signals in the F2 or the F3 was low. Again, no such intense signal was detected in the small follicles (less than $2 \mathrm{~mm}$ ) or in any other specimens hybridized with $\mathrm{S}$ (Fig. 3C). These results suggest that the expression of $Z P D$ gene in the granulosa cells is progressively increased during follicular development, especially at the final stages of follicular maturation.

\section{Biochemical properties of quail ZPD protein}

To confirm the presence of ZPD protein in the PL, we analyzed the PL proteins by means of gel 
A

-45 AgGACGCAGCTGGCTGCGGGTGGGCAAGTGTGGAGTGGTCTGGCA

1 ATGGAAGGGACTGTGACATATTTGCTGCTGTTCTCTGCCCTGCGCCTGGCTGGCTGTGTAGGCAACAAGAGTGAGCTGGTAAGCCCGCACAGCTCGAGGGGAAGGTTTACCCTGCGTGCC

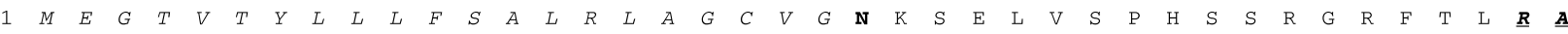

121 AAGAGGAGCTCAGATGCCTGCATGCCCAACCCGTGCCAGCACCATGGGAGCTGCCAGGTGATAAAGGACAGACCCATCTGCAGCTGCAAACCTGGCTTCACAGGGGCATTCTGCCAAGAT

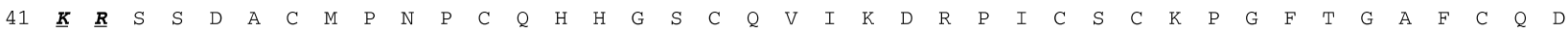

241 GTGGTACTGAAGTTGGCCTGTGAGGAAGAGCACATGAAGATGATGGTGAGGAAGGAGGTGTTTGAACAATTGAAAATCCCCCGGGAACTTGTCCACTTGAAGAACCAGGCATGCAAAGTT

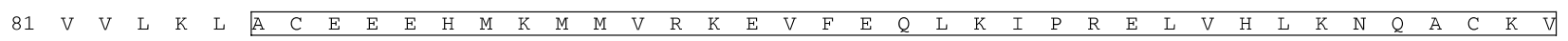

361 TCAGAAAGGGAAGAGGAGGGTGAGCTGTTTTTTGCAGCCACTCTTACAGGTGAAAACCACACTGCCTGTGGATCAATAATTCAGCAAAACAACTCCCATGTGTCATACTCCAACATCATT

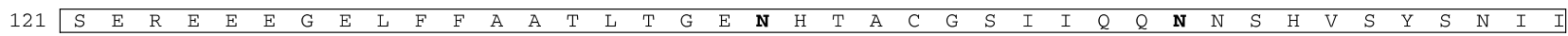

481 GAGACAGCGAAGGAAGCACACAGGGGTGTGATCTCCAGGAGCTTTCAGCTGGAGGTGCATTTCTCCTGTGTCTACGCCTATGAGCAGGTGGTGAAGATGCCATTTGCTCTCACCCCTGTC

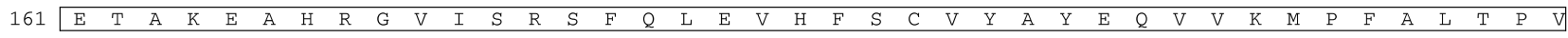

601 GACAAGCTGGTACAGTTCTTGGTCAGAGAAGGGCACTTCAACGTCAGCATGAGGCTGTACAAGACTGCATCCTACCTTGAGCCCTACCACCTGCCAACTGCAGCCGTGCCCATCACAGAC

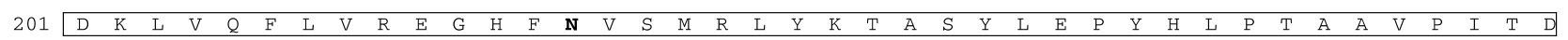

721 ACACTGTATGTCATGCTGAAGATAGAAGGGCAGCACCAGCTCCGGTACTTCCTGCTGAGTGTGGAGGGCTGCTGGGCCACACCAAGTGCAGATCCCTACCAGGATGTGCGACATGAGCTC

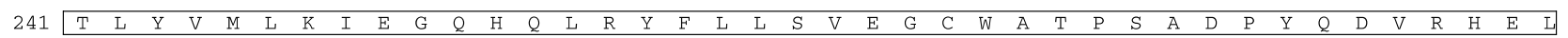

841 ATTGAGCAGGGGTGTCCCCATGATGAGACAGTGACATACTTAAATGCCGTTGGAGAGAGCACCACAGCCAAGTTCAGCTTCCAGATGTTTCAGTTTGTAGGGTACCCTGAGGTGTTCCTG

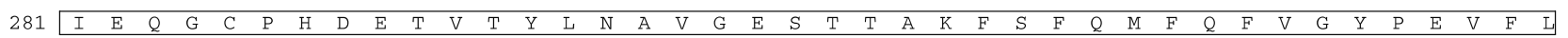
961 CACTGCCGTGTCCGGCTGTGTCTCCCTGATGGCCCTGAGCCCTGTGCCAAGCAATGTCCCACTCTCTGGAGGAGCAAGCGGGCGCTGGCAGATGACTACAATAAAATTGTCTCCTATGGA

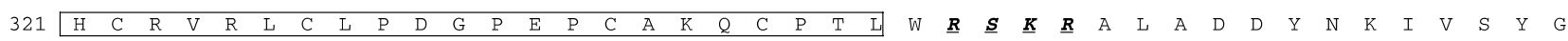
1081 CCCATCCACCTGCTGGCTGCTCCTTCCCTGGAAGTGGAGAGCCATCATCCCAGGGCTGACCAACAGGAGCTGAAGGGACCCGGCCTGTGGCTCCCCAGGATCCTCATCCTGCTGTGTGTG

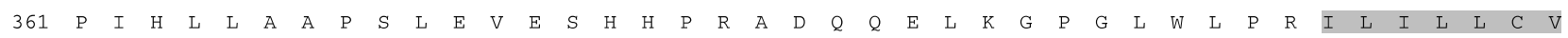
1201 CTTGGTGTGCTCACCGTGGTTGCTGCAGCTGCAGCTGTCAGCATCAGAAGACGGATGGTGTAGAAAATAGCCAGTTCCAAATAAATGTGGCAGCGGCAAAAAAAAAAAAAAAAAAAAAAA $\begin{array}{llllllllllllllllllllllll}401 & \mathrm{~L} & \mathrm{G} & \mathrm{V} & \mathrm{L} & \mathrm{T} & \mathrm{V} & \mathrm{V} & \mathrm{A} & \mathrm{A} & \mathrm{A} & \mathrm{A} & \mathrm{A} & \mathrm{V} & \mathrm{S} & \mathrm{I} & \mathrm{R} & \mathrm{R} & \mathrm{R} & \mathrm{M} & \mathrm{V} & \text { * }\end{array}$ 1321 A

\section{B}

Quail

Chicken

Xenopus

Quail

Chicken

Xenopus

Quail

Chicken

Xenopus

Quail

Chicken

Xenopus

Quail

Chicken

Xenopus

Quail

Chicken

Xenopus

Quail

Chicken

Xenopus

Quail

Chicken

Xenopus
MEGTVTYLLLFSALRLAGCVGNKSELVSPHSSRGRFTLRAKRSSDACMPNPCQHHGSCQV MEGTVTYLLLFSALRLAGCEGN* SELVS *HNSR * RFA $* \overline{\text { RAK }^{\star}} \mathrm{S} *$ DACVPNPCQHHGGCQV

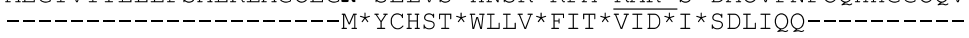

IKDRPICSCKPGFTGAFCQDVVLKLACEEEHMKMMVRKEVFEQLKI PRELVHLKNQACKV IEDRPICSCKPGFTGAFC *DVVLK*A*EEEHMKMMVRKE * FEL * $K^{\star}$ PRELV* LK* $Q A$ * KV ----------------*NEMAD*K*DNDQ**ITLLSS *LDE*D*NASQL *MN *PL *NM

SEREEEGELFFAATLTGENHTACGS I IQQNNSHVSYSNI IETAKEAHRG------VISRS

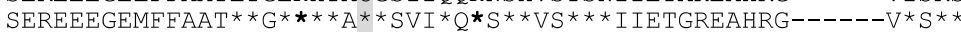

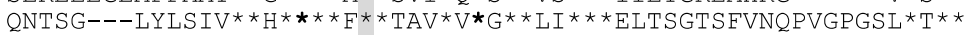

FQLEVHFSCVYAYEQVVKMPFALTPVDKLVQFLVREGHFNVSMRLYKTASYLEPYHLPTA

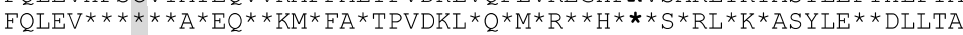

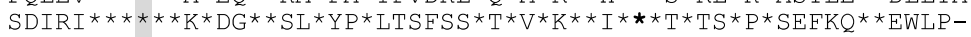

AVPITDTLYVMLKIEGQHQLRYFLLSVEGCWATPSADPYQDVRHELIEQGCPHDETVTYL

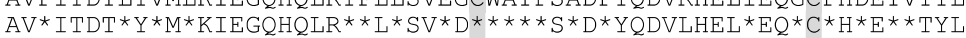
$V I * L_{S Q N} N^{*} Q * Q V H E H D L D N * * S * R I * D * \star * \star * T * N * E D K I R Y P I * S S * Y * N * T * * A M I$

NAVGESTTAKFSFQMFQFVGYPEVFLHCRVRLCLPDGPEPCAKQCPTLWRSKRALADDYN

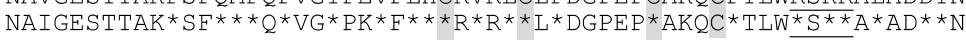

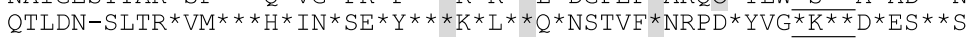

KIVSYGP IHLLAAPS LEVESHHPRADQQELKGPGLWLPRILILLCVLGVLTVVAAAAAVS $\star * * * * * * * \mathrm{H}^{*} \mathrm{~L} * \mathrm{~A} *$ SLR $* *$ SHHPRADQQE $* \mathrm{~K} *$ PSLWLPGILILLC $*$ LGVLTMAAAAVSRR

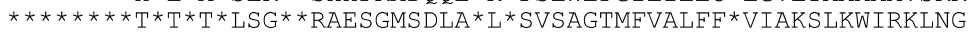

IRRRMV----

RRMV ------

PTTYKVQATP

Figure 1 (A) Nucleotide and deduced amino acid sequences of quail ZPD cDNA. The deduced amino acid is represented as a single-letter abbreviation shown below the nucleotide sequence (GenBank accession number: AB301422). The signal sequence (italic letters), the zona pellucida domain (ZP domain, white box), the consensus site for $\mathrm{N}$-glycosylation (bold letters), the consensus furin-cleavage site (bold letters with underlining), a poly adenylation signal sequence (underlining), and the putative transmembrane domain (shaded box) are indicated. The asterisk indicates the termination codon. (B) Alignment of amino acid sequence of quail, chicken, and Xenopus ZPD. Conserved residues are shown in asterisk and the consensus site for $\mathrm{N}$-glycosylation is in bold letters, and the consensus furin-cleavage site is underlined. Conserved Cys residues are indicated with a shaded box. 


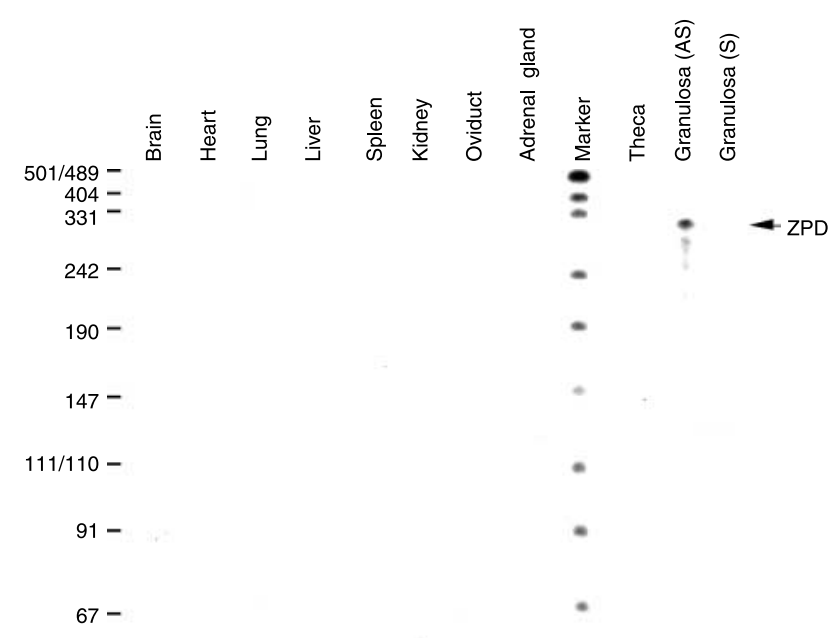

Figure 2 Tissue-specific expression of $Z P D$ mRNA. RNase protection assays were performed to detect the mRNA expression of the ZPD gene. We hybridized $15 \mu \mathrm{g}$ total RNA isolated from brain, heart, lung, spleen, kidney, oviduct, adrenal gland, theca layers of the largest follicles, and granulosa layers of the largest follicles with riboprobes specific to ZPD. In case of the RNA isolated from the granulosa cells, we also hybridized it with sense probes (S) instead of antisense probes (AS). Protected fragments were detected by autoradiography. The results shown are representative of repeated experiments.

electrophoresis. Under non-reducing conditions, three major bands migrating around 175, 97, and $35 \mathrm{kDa}$, which corresponds to dimeric and monomeric ZP1s and ZP3 respectively, were visualized in the PL extract after Coomassie Brilliant Blue R250 (CBB) staining (Fig. 4A, lane 1). These results are consistent with our previous reports (Sasanami et al. 2002). No other prominent
A
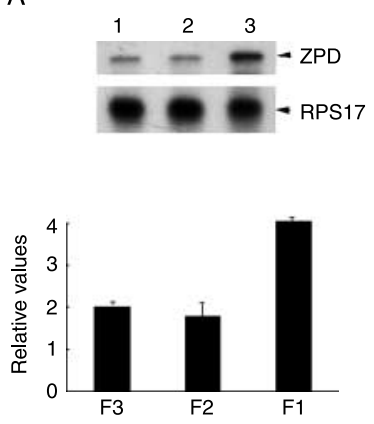

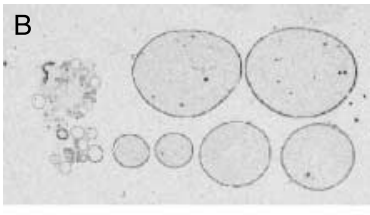

C

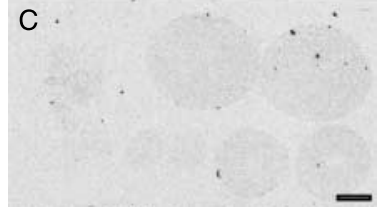

Figure 3 Expression pattern of ZPD mRNA during follicular development. (A) Autoradiograms of protected fragments. The $5 \mu \mathrm{g}$ total RNA the granulosa layer isolated from the third (lane 1), the second (lane 2), or the largest follicles (lane 3) were hybridized with the indicated riboprobes (ZPD or RPS17). Shown in upper panel are representative autoradiograms of triplicate experiments. Data shown in lower panel are represented as the mean \pm s.D. of triplicate experiments (each value was normalized against an RPS17 control). (B and C) In situ hybridization of quail ovary. Autoradiograms of ovarian sections after hybridization with ${ }^{33} \mathrm{P}$-labeled antisense probe specific to ZPD are shown (B). Control hybridization with ${ }^{33} \mathrm{P}$-labeled sense probe is depicted in (C). Scale bar, $5 \mathrm{~mm}$. The results are representative of repeated experiments.
A

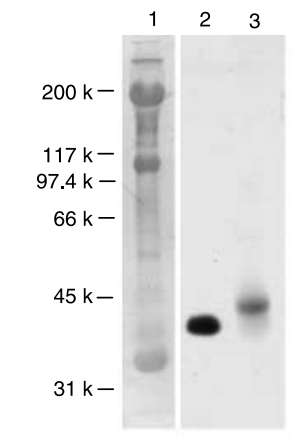

C
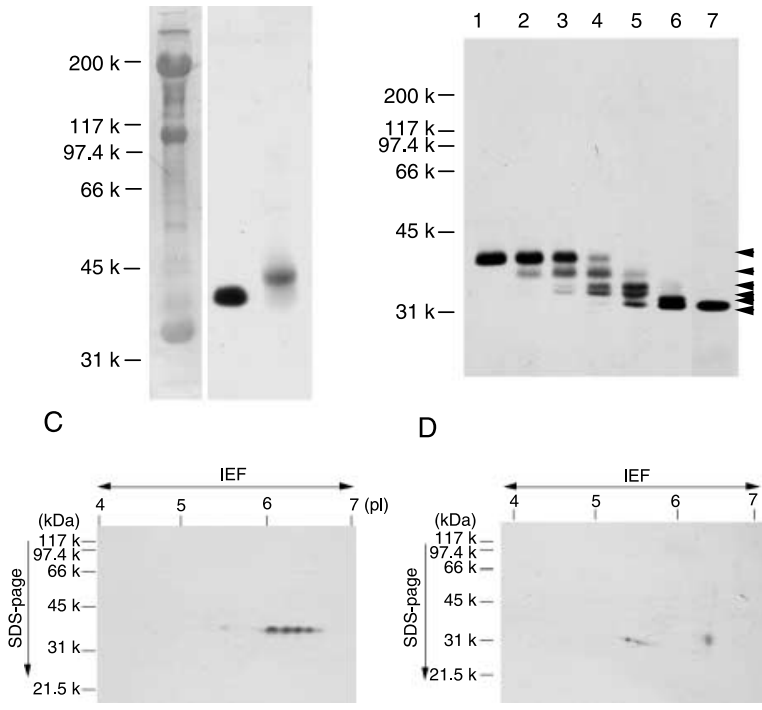

D

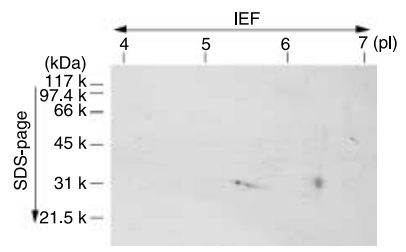

Figure 4 Western blot analysis of ZPD protein in the PL extract. (A) The PL extract $(30 \mu \mathrm{g})$ was transblotted onto a PVDF membrane after separation on SDS-PAGE under non-reducing conditions and stained with Coomassie Brilliant Blue R 250 (lane 1). The sample separated under non-reducing (lane 2, $1 \mu \mathrm{g} /$ lane) or reducing (lane 3, $10 \mu \mathrm{g} /$ lane) conditions was probed with anti-quail ZPD (1:10 000 dilution). The blots shown are representative of three experiments. (B) The PL extract $(2 \mu \mathrm{g}$ ) was digested with 0 (lane 1), 15 (lane 2), 20 (lane 3), 25 (lane 4), 30 (lane 5), 40 (lane 6), or 50 units (lane 7) of PNGase F as described in Materials and Methods. Samples were then separated on SDS-PAGE under non-reducing conditions, transblotted onto PVDF membrane, and detected with anti-quail ZPD antibody (1:10 000). The $40 \mathrm{kDa}$ ZPD and five bands with faster mobility are indicated by arrowheads. Note that lane 6 contains a doublet bands. The results shown are representative of repeated experiments. (C) Two-dimensional gel electrophoresis. $50 \mu \mathrm{g}$ of the PL extract was first separated by isoelectric focusing (IEF; pH 4-7), then subjected to SDS-PAGE under nonreducing conditions, and detected by means of western blotting. Theoretical pl values are indicated on the top of the panel. Shown are representative of repeated experiments. (D) The $50 \mu \mathrm{g}$ of the PL extract was digested with 1250 units of PNGase F as described in Materials and Methods. They were then separated on two-dimensional gel electrophoresis as described in the legend for (C). The results shown are representative of repeated experiments.

bands were detected, suggesting that the ZPD protein could be a minor component of the PL. To visualize the ZPD protein in the PL extract, we produced a specific antibody to quail ZPD and performed western blot analysis. As shown in the figure, our anti-ZPD antibody reacted well with the band with $40 \mathrm{kDa}$ in the PL extract under non-reducing conditions (Fig. 4A, lane 2). When the sample was separated under reducing conditions, a retarded mobility shift of the immunoreactive band was observed (43 kDa, Fig. 4A, lane 3). Although we were not able to determine the reasons for this result, the intensity of the immunoreactive band under reducing conditions became very weak in comparison with that of the band under non-reducing conditions. No band was 
detected when the sample was reacted with normal rabbit serum (data not shown), which suggests that our anti-ZPD antibody is specific to $40 \mathrm{kDa}$ ZPD protein. These results suggest that the immunoreactive materials that reacted with anti-ZPD antibody exist in the quail PL extract, and it might possess the intra-molecular disulfide bond(s) in the molecule, since the retarded mobility shift was observed when the proteins were denatured to reduce the proteins in the presence of mercaptoethanol.

The carbohydrate moieties of the ZPD protein were analyzed by digestion with PNGase F (Fig. 4B). The mobility of the immunoreactive band on SDS-PAGE increased in correspondence with the amount of the enzymes added, and five bands with higher mobilities were detected, indicating that the quail ZPD might carry multiple $N$-linked oligosaccharides. The change in the apparent molecular weight of ZPD after PNGase F digestion was estimated at $8 \mathrm{kDa}$. This value corresponds appropriately with the calculated molecular mass $(34.7 \mathrm{kDa})$ of the putative mature protein without the $\mathrm{N}$ - and C-terminal fragments from the nascent precursor protein $\left(\mathrm{Ser}^{43}-\mathrm{Arg}^{347}\right)$, removed by furin-like protease.

To investigate the biochemical properties of ZPD protein further, we performed two-dimensional gel electrophoresis (Fig. 4C and D). The $40 \mathrm{kDa}$ band that appeared in the one-dimensional SDS-PAGE under nonreducing conditions was separated further into four major spots that ranged from $\mathrm{pl}$ values of $6-7$ by isoelectric focusing (Fig. 4C). A faint immunoreactive spot was also seen in the position of pl around 5.5. To confirm the effect of $\mathrm{N}$-glycosylation of the protein on the $\mathrm{pl}$ value, we digested the PL extract with PNGase F and performed two-dimensional gel electrophoresis followed by western blot analysis. As shown in Fig. 4D, multiple spots detected in the absence of PNGase F in Fig. 4C are mainly converged into a single spot with pl around 6.5. Although the nature is not known, several spots in the position of $\mathrm{pl}$ around 5.5 were also detected. These results suggested that several ZPD isoforms detected as multiple spots with different $\mathrm{pl}$ value might possess different types or different numbers of $\mathrm{N}$-linked oligosaccharides in the molecule.

\section{Accumulation of ZPD protein during follicular growth}

In the next experiments, we investigated the accumulation of the ZPD protein in the PL during follicular development by western blot analysis. As shown in Fig. 5, F4 extract contains a small amount of immunoreactive proteins $(0.43 \pm 0.59$, mean \pm s.D. of arbitrary unit), but the intensity of the band increases in correspondence with the follicular growth (F3; $1.06 \pm 0.7 .2, \quad F 2 ; 2.17 \pm 0.54)$. The intensity reached the maximum level when the PL was isolated from the largest follicle $(2.95 \pm 0.08)$. These results suggested that the ZPD protein accumulated in accordance with follicular growth.
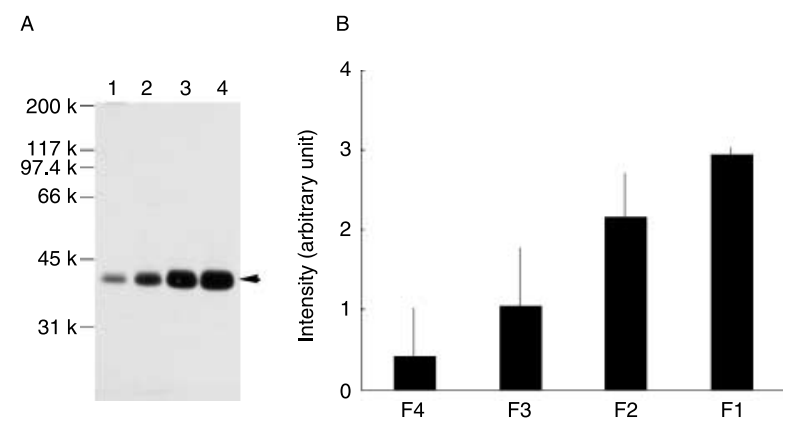

Figure 5 Accumulation of ZPD protein during follicular development. (A) Aliquots ( $3 \mu \mathrm{g}$ protein per lane) of the SDS-solubilized PL isolated from the largest (F1), the second largest (F2), the third largest (F3), and the fourth largest (F4) preovulatory follicles were subjected to western blot analysis using anti-quail ZPD antibody (1:10 000). Representative blots are shown. (B) The signals were quantified as an arbitrary unit, and the data in the figure were expressed as mean \pm s.D. of the arbitrary unit of three independent experiments.

\section{Localization of ZPD protein in the ovary}

To investigate the localization of ZPD protein in the follicles, we prepared paraffin sections of preovulatory follicles in various sizes and analyzed them by immunohistochemistry. As shown in Fig. 6A, the immunoreactive material recognized by anti-quail ZPD antibody accumulated in the PL apposed to the apical surface of the granulosa cells of the largest follicle. In agreement with the data of western blotting shown in Fig. 5, the amount of immunoreactive substances was low in the F3 follicles (Fig. 6B) and was the below the detection level in the small yellow follicles (Fig. 6C). No positive immunostaining was seen when the sections were stained with normal rabbit serum (Fig. 6D-F). These results indicate that ZPD could be selectively transported and secreted toward the apical surface of granulosa cells, which are apposed to the $\mathrm{PL}$, and accumulate in the PL during follicular development.

\section{Effect of FSH on the secretion of ZPD protein in the cultured granulosa cells}

To investigate the effects of gonadotropic hormone on ZPD production, the granulosa cells isolated from the largest (F1), the second largest (F2), or the third largest (F3) follicles were cultured for $48 \mathrm{~h}$ with or without FSH. The culture media were collected and subjected to western blotting to detect the effects of the hormone on ZPD protein contents. As shown in Fig. 7, the immunoreactive band of ZPD was detected in the control medium (without FSH) irrespective of follicular development. The intensity of immunoreactive band of ZPD in the control medium increased when the follicle developed from F3 to F2. Although the addition of FSH caused no effect on the secretion of ZPD by F1 and F2 derived granulosa cells, the amount of ZPD in the medium was significantly increased by FSH stimulation in the case of F3 cells. 

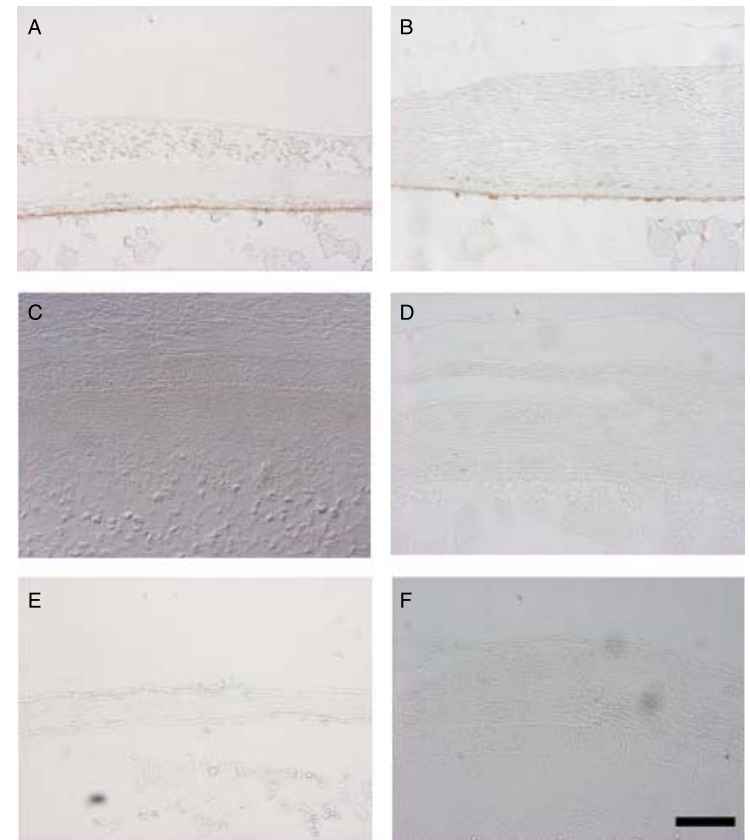

Figure 6 Immunohistochemical analysis of ZPD in follicular wall. Sections of follicular wall obtained from the largest ( $A$ and $D)$, the third largest (B and $\mathrm{E})$, and small yellow follicles $(\mathrm{C}$ and $\mathrm{F})$ were processed for immunohistochemical observation using anti-quail ZPD antibody (A-C; 1:300) or normal rabbit serum (D-F; 1:300). The results shown are representative of repeated experiments. Scale bar, $50 \mu \mathrm{m}$.

\section{Discussion}

As reported previously in our studies, quail granulosa cells produce ZP3, which is one of the components of the PL (Pan et al. 2001), whereas another constituent, ZP1, is synthesized in the liver (Sasanami et al. 2003b). In the present study, we found that another minor constituent, ZPD, was produced and secreted from the granulosa cells in Japanese quail. A recent study in the chicken has also demonstrated that the expression of $Z P D$ is restricted to granulosa cells (Okumura et al. 2004). However, the origin of ZPD in the $X$. laevis is the oocyte itself (Lindsay et al. 2002). Although no ZPD homolog has been identified in mammalian species, the expression of ZP glycoproteins appears to be regulated differently in different species. There is clear evidence showing that ZP3 is synthesized by the oocytes themselves in mice (Bleil \& Wassarman 1980) and in Xenopus (Yamaguchi et al. 1989), whereas the granulosa cells in the follicles also participate in the formation of ZP3 in rabbits (Lee \& Dunbar 1993) and in cynomolgus monkeys (Martinez et al. 1996). On the other hand, a glycoprotein homologous to ZP3 in chorion, the fish egg envelope, is produced in the liver and transported to the ovary by the blood circulation, like vitellogenin (Hamazaki et al. 1985, 1989). Thus, it is also possible that the expression of $Z P D$ in birds and frogs could be regulated differently. Although the hormonal regulation of frog ZPD biosynthesis had not been investigated yet,
A
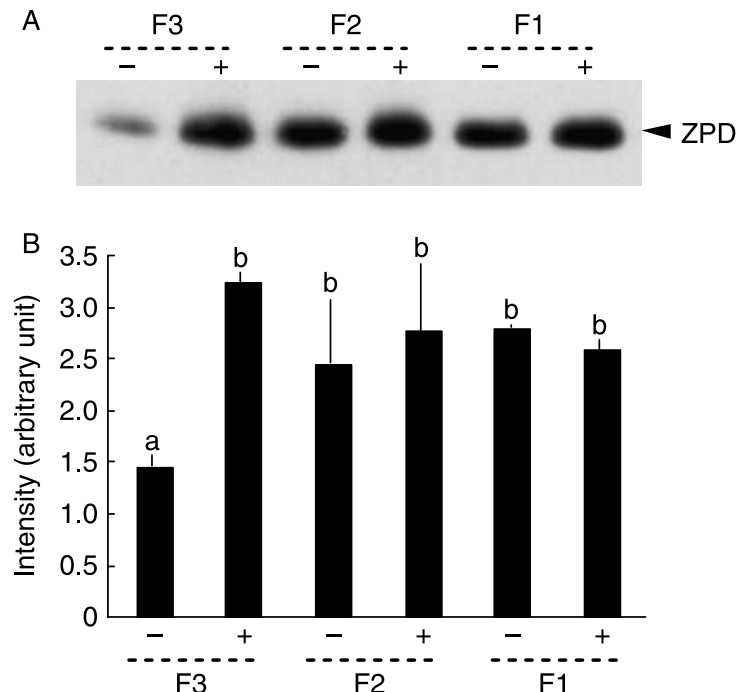

Figure 7 Effect of FSH on ZPD protein secretion. (A) Granulosa cells isolated from the largest (F1), the second largest (F2), or the third largest (F3) follicles were cultured with (+) or without (-) $100 \mathrm{ng} / \mathrm{ml} \mathrm{FSH}$ for $48 \mathrm{~h}$. The ZPD protein in the medium was detected using anti-quail ZPD antibody. Immunoblots shown here are representative of three experiments. (B) The signals were quantified as an arbitrary unit, and the data in the figure were expressed as mean \pm s.D. of the arbitrary unit of three independent experiments. Values with different superscripts are significantly different $(P<0.01)$.

our current study indicated that the secretion of ZPD protein from the cultured granulosa cells isolated from the immature follicles was stimulated by FSH. This result suggests that $\mathrm{FSH}$ plays a role in stimulating the secretion of ZPD protein in quail granulosa cells. In analogous situation, we previously reported that the secretion of ZP3 by the cultured granulosa cells also stimulated with the supplementation of FSH in the medium (Pan et al. 2003).

From the deduced amino acid sequence analysis of quail ZPD, we found that there is a consensus furincleavage site in the $\mathrm{N}$-terminal region upstream of its $\mathrm{ZP}$ domain in addition to the C-terminal one, which is common in all known ZP glycoproteins (Rankin \& Dean 2000, Jovine et al. 2005). The C-terminal consensus furin-cleavage site is suggested to be involved in the modification of precursor to form the mature ZP glycoprotein in various species (Lischer et al. 1999, Kubo et al. 1999, Sasanami et al. 2002, Yonezawa \& Nakano 2003). In addition to the role of the consensus furin-cleavage site in the biosynthesis of ZP glycoproteins, it is also reported that the removal of the C-terminal fragments at this site controls the secretion/ release of the ZP glycoprotein from the cells in mice (Jovine et al. 2002, 2004, 2005). The results of our previous study in Japanese quail also suggest this C-terminal proteolytic processing is a prerequisite for ZP3 secretion from the cells (Sasanami et al. 2003c). 
Although the participation of the consensus furincleavage sites for ZPD biosynthesis has not yet been elucidated, it is quite interesting to investigate the role of $\mathrm{N}$-terminal proteolytic processing in the ZPD production, since the presence of two peptidase sites in the sequence is the unique feature of avian ZPD protein.

Another feature of quail ZPD is that there are four potential $\mathrm{N}$-glycosylation sites in the amino acid sequence, and from the $\mathrm{N}$-terminal amino acid sequence analysis, there might be three sites in the mature protein. In our results, more than four bands with faster mobility that reacted well with anti-quail ZPD antibody were seen after PNGase F digestion (Fig. 4B), suggesting that multiple Asp residues might be occupied by $\mathrm{N}$-linked oligosaccharides, though direct evidence of this was not obtained. In two-dimensional electrophoresis, four immunoreactive spots were detected after the isoelectric focusing. The presence of these multiple spots with similar molecular mass is probably due to the differences of post-translational modifications in each ZPD isoform. (e.g., glycosylation, sulfation, etc.). This statement is also supported by the result of the present study that the digestion of the PL extract with PNGase $F$ results in the convergence of multiple spots mainly into a single spot with $\mathrm{pl}$ around 6.5. This value is similar to the calculated $\mathrm{pl}$ value of the mature ZPD peptide backbone (i.e., pl 6.28).

The immunohistochemical study with anti-quail ZPD antibody showed that immunoreactive material is present only in the PL located in the apical side of the granulosa cells (Fig. 6). Therefore, ZPD might be selectively transported from the Golgi apparatus toward the apical surface of granulosa cells, which are apposed to the PL. Similarly, we found that the majority of the secreted ZP3 from polarized Madin-Darby canine kidney (MDCK) cells cultured in a dual chamber apparatus were detected in the apical compartment, but not in the basolateral side chamber (Sasanami et al. 2005). Moreover, when a ZP3 mutant without the consensus sequence for $\mathrm{N}$-glycosylation was transfected into the cells, the ZP3 lacking the $\mathrm{N}$-glycans was detected in both the apical and basolateral media (Sasanami et al. 2005). These results indicated that ZP3 expressed in MDCK cells is selectively released to the apical compartment, and that the $\mathrm{N}$-linked carbohydrates might possess information that causes the efficient transport of ZP3 to the apical surface of the cells. Although we do not know whether the $\mathrm{N}$-glycans attached on the ZPD possess a functional role, efforts are currently in progress to investigate the topology of ZPD secretion in which ZPD selectively secreted to the apical surface of the granulosa cells forms the PL.

In our previous study, western blot analysis using specific antisera indicated that ZP1 was first detected when the granulosa layer was isolated from the fourth largest follicle, and the intensity of the band was dramatically increased after the follicle matured to the third largest size. On the other hand, immunoreactive ZP3 appeared as early as in the granulosa layer obtained from the small yellow follicles, and the intensity of the immunoreactive band increased progressively during follicular development. These results demonstrated that the accumulation of ZP1 was not synchronized with that of ZP3 in the PL during follicular development (Sasanami et al. 2004). In the present study, we found that the contents of ZPD protein in the PL as well as its transcripts in the cells increased during follicular development, especially at the latter stages of folliculogenesis, similar to ZP1 accumulation. Based on these observations, we suggest that the accretion of ZP3 protein on the surface of the oocyte by an unknown mechanism might trigger the ZP1 binding to the PL, and that the ZP1 accumulation leads to the association of ZPD protein in the PL. Okumura et al. reported that in the chicken the ZPD protein might bind loosely to the PL because it is released by the ultra sonication treatment without urea, though the binding partner is not known. From the in vivo accumulation pattern of ZPD in the present study, we speculate that the binding partner of ZPD might be ZP1 but not ZP3, though the experimental evidence has not been obtained. This is very likely the case, since the $\mathrm{pl}$ value of ZP1 is around 8-9, whereas that of ZPD as well as ZP3 ranges from 5 to 7 (data not shown). This statement is also supported by our previous finding that the radiolabeled ZP3 protein failed to visualize the ZPD band when the total PL extract was detected by ligand blot analysis (Ohtsuki et al. 2004, Sasanami et al. 2006). The question of whether such interaction between ZPD and ZP1 actually occurs during the PL formation remains to be resolved, and the elucidation of the role of ZPD protein in the formation of the insoluble PL fiber must await future analysis.

\section{Materials and Methods}

\section{Animals and tissue preparation}

Female Japanese quail, Coturnix japonica, 15-30 weeks of age (Tokai-Yuki, Toyohashi, Japan), were maintained individually under a photoperiod of 14 light: 10 darkness (with the light on at $0500 \mathrm{~h}$ ) and were provided with water and a commercial diet (Tokai-Hokuriku Nosan, Chita, Japan) ad libitum. Animals were decapitated, and the preovulatory follicles were dissected and placed in physiological saline. The granulosa layer was isolated as a sheet of granulosa cells sandwiched between the $\mathrm{PL}$ and the basal laminae, as previously described (Gilbert et al. 1977). PL was isolated by the procedure described by Sasanami et al. (2002), and the isolated PL was confirmed to be free from the granulosa cells by phase contrast microscopy. All experimental procedures for the use and care of animals in the present study were approved by the Animal Care Committee of Shizuoka University (approval number, 19-13). 


\section{cDNA cloning of quail ZPD}

Total RNA was extracted from the granulosa cells of the largest follicles with a commercial kit, RNAiso (Takara Biomedicals, Otsu, Japan), according to the manufacturer's instructions. Messenger RNA was isolated using an oligotex-dT30 mRNA purification kit (Takara Biomedicals), according to the manufacturer's instructions, and was reverse transcribed using a Super Script II First-Strand Synthesis System for RT-PCR kit with oligo (dT) primer (Invitrogen). PCR was performed using degenerate primers (sense primer: $5^{\prime}$-TCTMACASRKGAAAACCACACT-3', antisense primer: 5'-ATKGGTCCATARGASACAATT- $3^{\prime}$ ) designed from the alignment of available sequences of frog ZPD (GenBank accession number: U44949) and chicken ZPD (GenBank accession number: $\mathrm{AB} 114441)$. PCR was performed in a $50 \mu \mathrm{l}$ volume with PCR buffer, $5 \mathrm{mmol} / \mathrm{I} \mathrm{MgCl}_{2}, 0.4 \mathrm{mmol} / \mathrm{I} \mathrm{dNTP}$, and $2.5 \mathrm{U}$ of Taq DNA polymerase (Takara EX Taq, Takara Biomedicals). Following the addition of cDNA as the template, the reaction mixtures were incubated at $94{ }^{\circ} \mathrm{C}$ for $1 \mathrm{~min}$ and amplified for 30 cycles. Each cycle consisted of 30 -s denaturation at $94{ }^{\circ} \mathrm{C}$, 30-s annealing at $51.7^{\circ} \mathrm{C}$, and 1 -min elongation at $72{ }^{\circ} \mathrm{C}$. The amplicon was separated on $1.0 \%(\mathrm{w} / \mathrm{v})$ agarose gel electrophoresis, and a band of the expected size was eluted from the gel with a rapid gel extraction system (Marligen Bioscience, Ijamsville, MD, USA) according to the manufacturer's instructions. Purified DNA was subcloned into pT7 Blue T-Vector (Novagen, Madison, WI, USA) and sequenced by dyeterminator chemistry on an Applied Biosystem Model 310 sequencer by the dideoxy-mediated chain-termination method (Sanger et al. 1977). Based on the sequence information of the presumptive ZPD cDNA amplicon, 3'-RACE was performed using the 3' RACE System for RACE (Invitrogen). A genespecific primer (5'-AGWRTRGAGGACTGCTGGGC-3') in combination with adaptor primers was used for $3^{\prime}$-RACE. For $5^{\prime}$-RACE, CDNA was synthesized with a gene-specific primer (5'-GCCCAGCAGCCCTCCACACT-3'), and RACE reaction was performed using the $5^{\prime}$ RACE System for RACE, Version 2.0 (Invitrogen). The gene-specific primer in combination with adaptor primers used was $5^{\prime}$-CACCTCCAGCTGAAAGCTCCT$3^{\prime}$. RACE amplicons were subcloned and sequenced as described above.

\section{Sequence computations}

Homology search by the position-specific iterated, basic local alignment search tool (PSI-BLAST) method (Altschul et al. 1997) and alignment of multiple protein sequences by the CLUSTAL W method (Thompson et al. 1994) were performed using the DNA Data Bank of Japan (http://www.ddbj.nig.ac.jp). The signal peptide and its putative cleavage site were predicted according to Nielsen et al. (1997) using SignalP v2 (http://www. cbs.dtu.dk/services/SignalP/).

\section{RNase protection assay}

PCR-amplified fragments derived from quail ZPD cDNA (345 nt; 172-516 of GenBank accession number AB301422) or quail RPS17 ribosomal protein cDNA (Yamamoto et al. 2003) were subcloned into pGEM-3Z vector (Promega Corporation). After linearization with appropriate restriction enzymes, radioactive AS or sense riboprobes were synthesized using Riboprobe in vitro Transcription System (Promega Corporation) and $\left[\alpha_{-}{ }^{32} \mathrm{P}\right]$ CTP (NEN Life Science Products, Boston, MA, USA). The RNA probes were hybridized with total RNA overnight and digested with RNase A and T1 (Tanaka et al. 1999). The protected RNAs were separated on $6 \%(\mathrm{w} / \mathrm{v})$ polyacrylamide/urea gels. The radioactive bands on the dried gels were detected with autoradiography with the aid of an intensifying screen (Kodak).

\section{In situ hybridization}

Birds were decapitated, follicles were immediately removed, and frozen sections were prepared. In situ hybridization was carried out as described previously (Yoshimura et al. 2000). The AS 45 mer oligonucleotide probe (nucleotides 162-206 of GenBank accession number AB301422) was labeled with $\left[{ }^{33} \mathrm{P}\right]$ dATP (NEN Life Science Products) using terminal deoxyribonucleotidyl transferase (Gibco). The $\mathrm{S}$ was also labeled as described above. Hybridization was carried out overnight at $42{ }^{\circ} \mathrm{C}$. Washing was performed at room temperature for $30 \mathrm{~min}$ and at $55^{\circ} \mathrm{C}$ for $40 \mathrm{~min}$ twice. After washing, slides were exposed to Biomax-MR film (Kodak) for 2 weeks.

\section{Culture of granulosa cells}

Granulosa layers were incubated for $10 \mathrm{~min}$ at $37^{\circ} \mathrm{C}$ with $500 \mathrm{U} / \mathrm{ml}$ collagenase (Type I, Sigma Chemical Company) in Hanks' balanced salt solution (Hanks' BSS). Dispersed cells were washed thrice with RPMI 1640 medium (Gibco/Life Sciences) containing $25 \mathrm{mmol} / \mathrm{ml}$ Hepes and antibiotics (100 U/ml penicillin and $75 \mathrm{U} / \mathrm{ml}$ streptomycin) by repeated centrifugation at $80 \boldsymbol{g}$ for $3 \mathrm{~min}$ and finally suspended in RPMI 1640 medium containing 10\% (v/v) FCS, 25 mmol/ml Hepes and antibiotics. After counting the cell numbers by hematocytometer, the granulosa cells were inoculated in 24-well culture plates at a concentration of $1 \times 10^{5}$ viable cells per well and cultured in a humidified atmosphere of $5 \% \mathrm{CO}_{2}$ and $95 \%$ air at $41{ }^{\circ} \mathrm{C}$. The viability of the cell preparations was determined using the trypan blue exclusion technique (Roberts et al. 1994), and was greater than $95 \%$. After the initial plating period of $6 \mathrm{~h}$, the medium was changed to RPMI 1640 medium supplemented with or without ovine FSH $(100 \mathrm{ng} / \mathrm{ml})$. Ovine FSH (NIDDK-oFSH17) was generous gift from National Hormone and Pituitary Program (Baltimore, MD, USA) and the concentration of FSH was adopted from the studies of Pan et al. (2003) and Sasanami et al. (2003a). The cells were further cultured for $48 \mathrm{~h}$. Total volume of culture medium was adjusted to $0.8 \mathrm{ml}$ per well, and the granulosa cells used in all experiments were obtained from at least two birds. After the culture, the medium was collected and the debris was precipitated by centrifugation at $10000 \mathbf{g}$ for $10 \mathrm{~min}$. The supernatants after centrifugation were served as conditioned medium of the granulosa cells. The conditioned medium was stored at $-80{ }^{\circ} \mathrm{C}$ until use. 


\section{Production of antiserum against quail ZPD}

Rabbit polyclonal anti-quail ZPD antibody was raised against bacterially expressed His-tag fused with partial ZPD protein (from $\mathrm{Ser}^{43}$ to $\mathrm{Glu}^{262}$ ). Quail ZPD cDNA was amplified by PCR (cycling conditions: $94{ }^{\circ} \mathrm{C}$ for $1 \mathrm{~min}, 63{ }^{\circ} \mathrm{C}$ for $1 \mathrm{~min}$, and $72{ }^{\circ} \mathrm{C}$ for $1 \mathrm{~min}$ for 30 cycles) in order to introduce HindIII and Xbal sites upstream of the $\mathrm{Ser}^{43}$ and downstream of the Glu ${ }^{262}$ respectively. The sense and AS primers used were 5'-AAAAaagcttAGCTCAGATGCCTGCATGCCCAA-3' and 5'-AAAAtctagaCTCCACACTCAGCAGGAAGT-3' respectively. The PCR product containing the partial quail ZPD cDNA was digested with HindIII and Xbal, and ligated into pCold TF DNA vector (Takara Biomedicals) treated with the same restriction enzymes. The resulting construct was transformed into competent Escherichia coli, strain BL21 (Takara Biomedicals), and the ampicillin-resistant clone was selected after the nucleotide sequence analysis was performed. Recombinant quail ZPD was expressed in the presence of $1 \mathrm{mmol} / \mathrm{l}$ isopropyl- $\beta$-thiogalactopyranoside at $15{ }^{\circ} \mathrm{C}$ for $24 \mathrm{~h}$, and the protein was purified from the cell lysate using nickel resin (Novagen) according to the manufacturer's instructions.

A single female New Zealand White rabbit (SLC, Hamamatsu, Japan) was immunized with the recombinant quail ZPD (300 $\mu$ g protein) as described previously (Kuroki \& Mori 1995).

\section{Gel electrophoresis and western blot analysis}

The PL was extracted in SDS-Tris (1\% (w/v) SDS buffered at $\mathrm{pH}$ 6.8 with $70 \mathrm{mmol} / \mathrm{l}$ Tris- $\mathrm{HCl})$. Insoluble materials were removed by centrifugation at $14500 \mathrm{~g}$ for $15 \mathrm{~min}$, and clear supernatants served as PL extracts. Although we did not confirm whether the total protein of the PL was completely dissolved, using this method most of the PL disappeared during the extraction step, and visible precipitates after centrifugation were not found in our experimental conditions. The protein concentration in each sample was determined using a BCA Protein Assay kit (Pierce, Rockford, IL, USA).

SDS-PAGE under non-reducing or reducing conditions was carried out as described previously (Laemmli 1970), using 12 and $5 \%(\mathrm{w} / \mathrm{v})$ polyacrylamide for resolving and stacking gels respectively. For western blotting, proteins separated on SDSPAGE were transferred to a PVDF membrane (Immobilon-P, Millipore Bedford, MA, USA; Matsudaira 1987). The membrane reacted with anti-quail ZPD antibody (1:10 000) was visualized by means of a chemiluminescent technique (Amersham Pharmacia Biotech) using HRP-conjugated antirabbit IgG (Cappel, Durham, NC, USA) as a secondary antibody. Visualized blots were digitized using a Macintoshbased image analyzing system (NIH Image v.1.61).

Two-dimensional gel electrophoresis was performed using a Protean IEF Cell apparatus with IPG ReadyStrip ( $\mathrm{pH}$ range: 4-7, length: $7 \mathrm{~cm}$, BioRad). The PL isolated from the largest follicles was dissolved in sample preparation buffer ( $8 \mathrm{~mol} / \mathrm{l}$ urea, $0.2 \%$ (w/v) 3-[(3-cholamidopropyl) dimethylammonio]-2-hydroxypropanesulfonic acid, $0.2 \%(\mathrm{w} / \mathrm{v})$ ampholine, and $0.001 \%$ $(\mathrm{w} / \mathrm{v})$ bromophenol blue). Aliquots $(50 \mu \mathrm{g})$ were then applied to the IPG ReadyStrip, and were separated by isoelectric focusing under the standard procedure suggested by the manufacturer.
They were then subjected to SDS-PAGE under non-reducing conditions as described above. Separated proteins were detected with $\mathrm{CBB}$ staining or western blotting with antiquail ZPD antibody as described above.

\section{PNGase F digestion}

The PL extract was digested with PNGase F, an amidase that cleaves between the innermost $\mathrm{N}$-acetylglucosamine and asparagines residues of $\mathrm{N}$-linked glycoproteins (E.C.3.5.1.52; New England Biolabs, Beverly, MA, USA), according to the manufacturer's instructions. Briefly, the PL extract was mixed with $1 / 10$ volume of $10 \times \mathrm{G} 7$ buffer $(0.5 \mathrm{~mol} / \mathrm{l}$ sodium phosphate, $\mathrm{pH} 7.5)$ and $10 \%(\mathrm{v} / \mathrm{v}) \mathrm{NP}-40$. The mixture was incubated in the presence or absence of PNGase $\mathrm{F}$ at $37^{\circ} \mathrm{C}$ for $20 \mathrm{~h}$. It was then separated on one-dimensional SDS-PAGE or two-dimensional gel electrophoresis, and the ZPD band was detected with western blotting as described above.

\section{$N$-terminal sequence analysis of ZPD}

Aliquots (1 mg protein) of the PL extract separated on SDSPAGE were transferred to PVDF membranes as described above. After visualization of the bands by CBB staining, the band of ZPD was directly applied to an automated gas-phase protein sequencer (Model PPSQ-21A, Shimadzu Corporation, Kyoto, Japan).

\section{Immunohistochemical observation}

For localization of ZPD in the follicle, the preovulatory follicles were dissected, fixed in Bouin's fixative, and embedded in Paraplast (Oxford Labware, St Louis, MO, USA). Immunohistochemical techniques using anti-quail ZPD antibody (1:300) or normal rabbit serum (1:300) were described previously (Sasanami et al. 2002). The immunolabeled sections were examined under an interference-contrast photomicroscope (BX 50, Olympus Optics, Tokyo, Japan).

\section{Statistical analysis}

All experiments were repeated at least thrice. Data were analyzed for significant differences using ANOVA, and means were compared using Duncan's multiple range test. A $P$ value of less than 0.05 denoted the presence of a statistically significant difference.

\section{Declaration of interest}

The authors declare that there is no conflict of interest that would prejudice the impartiality of this scientific work.

\section{Funding}

This work was supported in part by a Grant-in-Aids for Scientific Research (18780210 to T Sasanami) from the Ministry of Education, Culture, Sports, Science, and Technology, Japan. 


\section{Acknowledgements}

The authors are grateful to Miss Ayako Katayama for technical assistance.

\section{References}

Altschul SF, Madden TL, Schaffer AA, Zhang J, Miller W \& Lipman DJ 1997 Gapped BLAST and PSI-BLAST: a new generation of protein database search programs. Nucleic Acids Research 25 3389-3402.

Bellairs R, Harkness M \& Harkness RD 1963 The vitelline membrane of the hen's egg: a chemical and electron microscopical study. Journal of Ultrastructure Research 8 339-359.

Bausek N, Waclawek M, Schneider WJ \& Wohlrab F 2000 The major chicken egg envelope protein ZP1 is different from ZPB and is synthesized in the liver. Journal of Biological Chemistry 278 28866-28872.

Bleil JD \& Wassarman PM 1980 Synthesis of zona pellucida proteins by denuded and follicle-enclosed mouse oocytes during culture in vitro. PNAS 77 1029-1033.

Bork P \& Sander C 1992 A large domain common to sperm receptors (ZP2 and ZP3) and TGF- $\beta$ type III receptor. FEBS Letters 300 237-240.

Conner SJ, Lefievre LL, Hughes DC \& Barratt CLR 2005 Cracking the egg: increased complexity in the zona pellucida. Human Reproduction 20 $1148-1152$.

Ganguly A, Sharma RK \& Gupta SK 2008 Bonnet monkey (Macaca radiata) ovaries, like human oocytes, express four zona pellucida glycoproteins. Molecular Reproduction and Development 75 156-166.

Gilbert AB, Evans AJ, Perry MM \& Davidson MH 1977 A method for separating the granulosa cells, the basal lamina and the theca of the preovulatory ovarian follicle of the domestic fowl (Gallus domesticus). Journal of Reproduction and Fertility 50 179-181.

Goudet G, Mugnier S, Callebaut I \& Monget P 2008 Phylogenetic analysis and identification of pseudogenes reveal a progressive loss of zona pellucida genes during evolution of vertebrates. Biology of Reproduction 78 796-806.

Hamazaki T, luchi I \& Yamagami K 1985 A spawning female-specific substance reactive to anti-chorion (egg-envelope) glycoprotein antibody in the teleost, Oryzias latipas. Journal of Experimental Zoology 235 269-279.

Hamazaki TS, Nagahama Y, luchi I \& Yamagami K 1989 A glycoprotein from the liver constitutes the inner layer of the egg envelope (zona pellucida interna) of the fish, Oryzias latipes. Developmental Biology $133101-110$

Harris JD, Hibler DW, Fontenot GK, Hsu KT, Yurewicz WC \& Sacco AG 1994 Cloning and characterization of zona pellucida genes and cDNAs from a variety of mammalian species: the ZPA, ZPB and ZPC gene families. DNA Sequence 4 361-393.

Hoodbhoy T, Joshi S, Boja ES, Williams SA, Stanley P \& Dean J 2005 Human sperm do not bind to rat zonae pellucidae despite the presence of four homologous glycoproteins. Journal of Biological Chemistry $\mathbf{2 8 0}$ 12721-12731.

Howarth B 1990 Avian sperm-egg interaction: perivitelline layer possesses receptor activity for spermatozoa. Poultry Science 69 1012-1015

Jovine L, Qi H, Williams Z, Litscher E \& Wassarman PM 2002 The ZP domain is a conserved module for polymerization of extracellular proteins. Nature Cell Biology 4 457-461.

Jovine L, Qi H, Williams Z, Litscher ES \& Wassarman PM 2004 A duplicated motif controls assembly of zona pellucida domain proteins. PNAS 101 5922-5927.

Jovine L, Darie CC, Litscher ES \& Wassarman PM 2005 Zona pellucida domain proteins. Annual Review of Biochemistry 74 83-114.

Kubo H, Matsushima M, Kotani M, Kawasaki H, Saido TC, Kawashima S, Katagiri C \& Suzuki A 1999 Molecular basis for oviductin-mediated processing from gp43 to gp41, the predominant glycoproteins of Xenopus egg envelopes. Developmental Genetics 25 123-129.

Kuroki M \& Mori M 1995 Origin of 33 kDa protein of vitelline membrane of quail egg: immunological studies. Development, Growth and Differentiation 37 545-550.
Laemmli UK 1970 Cleavage of structural proteins during the assembly of the head of bacteriophage T4. Nature 227 680-685.

Lee VH \& Dunbar BS 1993 Developmental expression of the rabbit 55-kDa zona pellucida protein and messenger RNA in ovarian follicles. Developmental Biology 155 371-382.

Lefievre L, Conner SJ, Salpekar A, Olufowobi O, Ashton P, Pavlovic B, Lenton W, Afnan M, Brewis IA \& Monk M 2004 Four zona pellucida glycoproteins are expressed in the human. Human Reproduction 19 $1580-1586$.

Lindsay LA, Yang JC \& Hedrick JL 2002 Identification and characterization of a unique Xenopus laevis egg envelope component, ZPD. Development, Growth and Differentiation 44 205-212.

Lindsay LL, Pwavy TR, Lejano RS \& Hedrick JL 2003 Cross-fertilization and structural comparison of egg extracullular matrix glycoproteins from Xenopus laevis and Xeopus tropicalis. Comparative Biochemistry and Physiology, Part A 136 343-352.

Lischer ES, Qi H \& Wassarman PM 1999 Mouse zona pellucida glycoproteins mZP1 and mZP3 undergo carboxy-terminal proteolytic processing in growing oocytes. Biochemistry 38 12280-12287.

Martinez ML, Fontenot GK \& Harris JD 1996 The expression and localization of zona pellucida glycoproteins and mRNA in cynomolgus monkeys (Macaca fascicularis). Journal of Reproduction and Fertility $\mathbf{5 0}$ 35-41.

Matsudaira P 1987 Sequence from picomole quantities of proteins electroblotted onto polyvinylidene difluoride membranes. Journal of Biological Chemistry 262 10035-10038.

McLeskey SB, Dowds CR, Carballada R, White RR \& Saling PM 1998 Molecules involved in mammalian sperm-egg interaction. International Review of Cytology 177 57-113.

Nielsen H, Engelbrecht J, Vrunak S \& von Heijne G 1997 Identification of prokaryotic and eukaryotic signal peptides and prediction of their cleavage sites. Protein Engineering 10 1-6.

Ohtsuki M, Hanafy AM, Mori M \& Sasanami T 2004 Involvement of interaction of ZP1 and ZPC in the formation of quail perivitelline membrane. Cell and Tissue Research 318 565-570.

Okumura H, Kohno Y, Iwata Y, Mori H, Aoki N, Sato C, Kitajima K, Nadano D \& Matsuda T 2004 A newly identified zona pellucida glycoprotein, ZPD, and dimeric ZP1 of chicken egg envelope are involved in sperm activation on sperm-egg interaction. Biochemical Journal 384 191-199.

Pan J, Sasanami T, Kono Y, Matsuda T \& Mori M 2001 Effects of testosterone on production of perivitelline membrane glycoprotein ZPC by granulosa cells of Japanese quail (Coturnix japonica). Biology of Reproduction 64 310-316.

Pan J, Sasanami T \& Mori M 2003 Stimulation of ZPC production by folliclestimulating hormone in the granulosa cells of Japanese quail (Coturnix japonica). Journal of Poultry Science 40 202-211.

Rankin T \& Dean J 2000 The zona pellucida: using molecular genetics to study the mammalian egg coat. Reviews of Reproduction 126 3847-3855.

Roberts RD, Sharp PJ, Burt DW \& Goddard C 1994 Insulin-like growth factor-I in the ovary of the laying hen: gene expression and biological actions on granulosa and thecal cells. General and Comparative Endocrinology 93 327-336.

Sanger F, Nicklen S \& Coulson AR 1977 DNA sequencing with chainterminating inhibitors. Biotechnology 24 104-108.

Sasanami T, Pan J, Doi Y, Hisada M, Kohsaka T \& Toriyama M 2002 Secretion of egg envelope protein ZPC after C-terminal proteolytic processing in quail granulosa cells. European Journal of Biochemistry $2692223-2231$.

Sasanami T, Atsumi E \& Mori M 2003 a Effect of follicle-stimulating hormone on ZPC protein secretion by quail granulosa layer. Animal Science Journal 74 217-222.

Sasanami T, Pan J \& Mori M 2003b Expression of perivitelline membrane glycoprotein ZP1 in the liver of Japanese quail (Coturnix japonica) after in vivo treatment with diethylstilbestrol. Journal of Steroid Biochemistry and Molecular Biology 84 109-116.

Sasanami T, Toriyama M \& Mori M 2003c Carboxy-terminal proteolytic processing at a consensus furin cleavage site is a prerequisite event for quail ZPC secretion. Biology of Reproduction 68 1613-1619. 
Sasanami T, Ohtsuki M, Hanafy AM \& Mori M 2004 Accumulation of ZP1 and ZPC in quail perivitelline membrane during follicular development. Journal of Poultry Science 41 289-293.

Sasanami T, Matsushima K, Ohtsuki M, Kansaku N, Hiyama G \& Mori M 2005 Vectorial secretion of perivitelline membrane glycoprotein ZPC of Japanese quail (Coturnix japonica) in polarized Madin-Darby canine kidney cells. Cells, Tissues, Organs 180 169-177.

Sasanami T, Ohtsuki M, Ishiguro T, Matsushima K, Hiyama G, Kansaku N, Doi Y \& Mori M 2006 Zona pellucida domain of ZPB1 controls specific binding of ZPB1 and ZPC in Japanese quail (Coturnix japonica). Cells, Tissues, Organs 183 41-52.

Sasanami T, Murata T, Ohtsuki M, Matsushima K, Hiyama G, Kansaku N \& Mori M 2007 Induction of sperm acrosome reaction by perivitelline glycoprotein ZP1 in Japanese quail (Coturnix japonica). Reproduction 133 41-49.

Smith J, Paton IR, Hughes DC \& Burt DW 2005 Isolation and mapping the chicken zona pellucida genes: an insight into the evolution of orthologous genes in different species. Molecular Reproduction and Development 70 133-145.

Spargo SC \& Hope RM 2003 Evolution and nomenclature of the zona pellucida gene family. Biology of Reproduction 68 358-362.

Takeuchi Y, Nishimura K, Aoki N, Adachi T, Sato C, Kitajima K \& Matsuda T 1999 A 42-kDa glycoprotein from chicken egg-envelope, an avian homolog of the ZPC family glycoproteins in mammalian zona pellucida. European Journal of Biochemistry 260 736-742.

Tanaka M, Yamamoto I, Ohkubo T, Wakita M, Hoshino S \& Nakashima K 1999 cDNA cloning and developmental alterations in gene expression of the two Pit-1/GHF-1 transcription factors in the chicken pituitary. General and Comparative Endocrinology 114 441-448.
Thompson DJ, Higgins DG \& Gibson TJ 1994 CLUSTALW: improving the sensitivity of progressive multiple sequence alignment through sequence weighting. Nucleic Acids Research 22 4673-4680.

Waclawek M, Foisner R, Nimpf J \& Schneider WJ 1998 The chicken homologue of zona pellucida protein-3 is synthesized by granulosa cells. Biology of Reproduction 59 1230-1239.

Wyburn GM, Aitken RNC \& Johnston HS 1965 The ultrastructure of the zona radiata of the ovarian follicle of the domestic fowl. Journal of Anatomy 99 469-484.

Yamaguchi S, Hedrick JL \& Katagiri C 1989 The synthesis and localization of envelope glycoproteins in oocytes of Xenopus laevis using immunocytochemical methods. Development, Growth and Differentiation 31 85-94.

Yamamoto I, Tsukada A, Saito N \& Shimada K 2003 Profiles of mRNA expression of genes related to sex differentiation of the gonads in the chicken embryo. Poultry Science 82 1462-1467.

Yonezawa N \& Nakano M 2003 Identification of the carboxyl termini of porcine zona pellucida glycoproteins ZPB and ZPC. Biochemical and Biophysical Research Communications 307 877-882.

Yoshimura T, Suzuki Y, Makino E, Suzuki T, Kuroiwa A, Matsuda Y, Namikawa T \& Ebihara S 2000 Molecular analysis of avian circadian clock genes. Molecular Brain Research 78 207-215.

Received 5 February 2008

First decision 4 April 2008

Revised manuscript received 19 October 2008

Accepted 18 November 2008 